\title{
Intraoperative blood pressure changes as a risk factor for anastomotic leakage in colorectal surgery
}

\author{
I. L. Post • P. M. Verheijen • A. Pronk • I. Siccama • \\ P. L. Houweling
}

Accepted: 24 November 2011 / Published online: 3 February 2012

(C) The Author(s) 2012. This article is published with open access at Springerlink.com

\begin{abstract}
Purpose Anastomotic leakage is a serious complication after colorectal surgery. Pre- and intraoperative factors may contribute to failure of colorectal anastomosis. In this study we have tried to determine risk factors for anastomotic leakage, with special emphasis on intraoperative blood pressure changes.

Methods During a 24-month period, patients receiving a colorectal anastomosis were prospectively evaluated. For each patient preoperative characteristics, intraoperative adverse events and surgical outcome data were collected. Blood pressure changes were calculated as a relative decrease $(>25 \%$ and $>40 \%$ ) from preoperative baseline values.

Results During the study period, 285 patients underwent colorectal surgery with an anastomosis. Fifteen patients developed an anastomotic leakage (5.3\%). All patients who developed a leakage had a left-sided procedure $(P<0.001)$. When blood loss was more than $250 \mathrm{~mL}(P=0.003)$ or an intraoperative adverse event occurred $(P=0.050)$, the risk for developing an anastomotic leakage was significantly increased. A preoperative high diastolic blood pressure of $\geq 90 \mathrm{mmHg}$ $(P=0.008)$ and severe intraoperative hypotension $[>40 \%$
\end{abstract}

\footnotetext{
I. L. Post $(\bowtie)$

Department of Anesthesiology, Academic Medical Centre,

Meibergdreef 9 ,

1105 AZ Amsterdam, The Netherlands

e-mail: i.l.post@amc.uva.nl

P. M. Verheijen · A. Pronk

Department of Surgery, Diakonessenhuis Hospital,

Utrecht, the Netherlands

I. Siccama $\cdot$ P. L. Houweling

Department of Anesthesiology, Diakonessenhuis Hospital,

Utrecht, the Netherlands
}

decrease in diastolic blood pressure $(P=0.049)]$ were identified as univariate risk factors for anastomotic leakage.

Conclusions The development of an anastomotic leakage after colorectal surgery is related to surgical, patient and anaesthetic risk factors. A high preoperative diastolic blood pressure and profound intraoperative hypotension combined with complex surgery, marked by a blood loss of $\geq 250 \mathrm{~mL}$ and the occurrence of intraoperative adverse events, is associated with an increased risk of developing anastomotic leakage.

Keywords Anastomotic leakage · Blood pressure · Colorectal surgery

\section{Introduction}

Anastomotic leakage is a serious complication occurring in gastrointestinal surgery. Morbidity and mortality increase considerably after the development of an anastomotic leakage. Several factors such as obesity [1], ASA score, emergency surgery [2], lower anastomotic level [3], male gender [4], smoking or alcohol abuse [5,6] and perioperative fluid management have been identified as independent risk factors for anastomotic failure.

Tissue ischemia at the site of the anastomosis is frequently cited and implicated as a cause for anastomotic breakdown [7, 8]. During anaesthesia, the blood pressure tends to decrease due to a variety of factors, including direct effects of the anaesthetic, inhibition of the sympathetic nervous system and loss of baroreceptor reflex control of arterial pressure. These changes can result in episodes of intraoperative hypotension and microvascular ischemia.

Although hypertension is not considered to be an independent risk factor for the development of cardiovascular complications [9], patients with pre-existing hypertension are 
more likely to experience intraoperative blood pressure variability [10]. This has led to a renewed interest in the association between intraoperative hemodynamic variability and adverse postoperative outcomes such as stroke, slow graft function after organ transplantation [11, 12], anastomotic leakage [13] and even 1-year mortality [14].

The influence of aberrant preoperative and intraoperative hemodynamic status on an adverse outcome following colorectal surgery has not been extensively studied. Our objective was to identify pre- and intraoperative predictive factors contributing to the failure of colorectal anastomoses, with a special emphasis on intraoperative blood pressure changes.

\section{Methods}

\section{Patients}

This prospective observational study was approved by the hospital ethics committee. During a 24-month period, 285 consecutive patients undergoing elective or emergency colorectal surgery with large bowel anastomoses in our institution were evaluated. The procedures included in this study were open or laparoscopic resections of colon or rectum. The reversal of a stoma was categorised as other. Past medical history and demographic data such as age, gender, body mass index (BMI), American Society of Anesthesiologists (ASA) risk classification, smoking and alcohol consumption were also collected. Physical examination and vital signs such as blood pressure and heart rate were recorded preoperatively in the outpatient clinic.

\section{Anaesthetic procedure}

Preoperative beta blockers were continued until surgery. All patients were premedicated with diazepam $10 \mathrm{mg}$ orally $60 \mathrm{~min}$ before induction. After arrival in the operating theatre, electrocardiogram tracing from leads II and V5 were displayed continuously. An intravenous drip and radial arterial line were inserted. The urinary bladder was catheterized in all patients. Unless contraindicated, all patients received an epidural catheter, at a level between T6 and T10. Before induction, all patients received an epidurally administered bolus injection of a mixture of levobupivacaine $0.5 \%$ and sufentanil $5 \mu \mathrm{g} / \mathrm{mL}$. Following induction of general anaesthesia with intravenously administered propofol, sufentanil and rocuronium, endotracheal intubation was performed. Controlled ventilation was adjusted to maintain end tidal $\mathrm{CO}_{2}$ between 35 and $45 \mathrm{mmHg}$. Anaesthesia was maintained with sevoflurane and $70 \%$ nitrous oxide in oxygen, muscle relaxation was preserved with incremental doses of rocuronium. A nasogastric tube was inserted and subsequently removed at the end of surgery. Central venous lines were only inserted on indication. Blood losses were accurately assessed and replaced by blood (packed cells) and fresh frozen plasma when the haemoglobin level fell under $8 \mathrm{~g} / \mathrm{dL}(5.0 \mathrm{mmol} / \mathrm{L})$. Initial blood losses were substituted with intravenous colloids. A base infusion of Ringer's lactate, $2-4 \mathrm{~mL} / \mathrm{kg} / \mathrm{h}$ was administered throughout the operation. Blood and intravenous fluids were warmed before administration. A heated forced air blanket was used to prevent a significant fall in body temperature. In the presence of insufficient analgesia (increased heart rate and blood pressure and/or signs of lacrimation and sweating), a bolus of sufentanil $(10 \mu \mathrm{g})$ was administered intravenously. Intraoperative blood pressure changes were calculated as a relative decrease $(>25 \%$ and $>40 \%$ ) in systolic and diastolic blood pressure from preoperative baseline values. If mean blood pressure decreased under $65 \mathrm{mmHg}$, an intravenous vasopressive agent was administered. Postoperatively an epidural patient controlled analgesia pump was used to provide analgesia.

\section{Surgical procedure}

Surgical factors such as previous abdominal surgery, preoperative radiotherapy, the indication for surgery, duration of surgery, complications during surgery and postoperative data were prospectively collected and recorded. All included patients, whether with benign or malignant pathology, entered a multi-modal rehabilitation program. Prior to surgery all patients were informed in detail about the perioperative enhanced recovery protocol, and were given an estimated length of stay. Families were also encouraged to participate, and to motivate the patient during the postoperative recovery.

Patients particularly at risk for respiratory complications received a preoperative consultation by a physiotherapist. Patients received carbohydrate-loaded drinks until $2 \mathrm{~h}$ before surgery, and received no bowel preparation. In cases of surgery on the left-sided colon or rectum, patients received an enema on the morning of the day of surgery. Perioperative antibiotics were given as a single intravenous shot of $2 \mathrm{~g}$ of cefazolin and $500 \mathrm{mg}$ of metronidazole. The trans-urethral urinary catheter was removed when patients could adequately mobilize. All patients were encouraged to be ambulant on the first postoperative day.

The decision to operate laparoscopically was based on patient characteristics (previous surgery, co-morbidity) and tumour characteristics (size, complexity, involvement of surrounding structures). Drains were only used on indication and in case of surgery in the lower pelvis.

All anastomoses were handsewn, except for colorectal anastomoses, which were achieved using a circular stapler. Gastric tubes were removed postoperatively before leaving the recovery room. Oral fluid intake was commenced on the same day as surgery. Oral food intake was commenced the day after surgery. 
Anastomotic leakage

Anastomotic leakage was suspected on clinical indications such as fever, tachycardia, pain, tenderness, peritonitis or purulent/faecal discharge from a drain. All suspected anastomotic leaks were proven by CT scan, ultrasound or after operative evidence was obtained.

Variables and risk factors

Various independent clinical variables were analysed. Patient age and body mass index were evaluated as continuous variables. Gender, smoking, co-morbidity and physical status (ASA $\leq 2$ or $\geq 3$ ) were evaluated as categorical variables. The use of alcohol was analysed as a categorical variable $(\leq 2$ or $\geq 3$ units a day). Indication for operation was categorised as carcinoma, benign or other. The occurrence of an intraoperative complication such as lesion of the spleen, bladder, ureter or ileum, severe bleeding or positive air bubble test was analysed as a categorical variable. Duration of surgery was evaluated as a continuous variable. Blood loss was evaluated as a continuous and categorical variable $(<250$ and $\geq 250 \mathrm{~mL})$. Preoperative diastolic $(<90$ and $\geq 90 \mathrm{mmHg}$ ) and systolic ( $<150$ and $\geq 150 \mathrm{mmHg}$ ) blood pressures were evaluated as continuous and categorical variable. The relative decrease in systolic and diastolic blood pressure from baseline values (preoperative measurements) during the operation were evaluated as continuous (in minutes) and categorical ( $>25 \%$ and $>40 \%$ ) variables.

\section{Statistical analysis}

The main object of this study was to identify potential predictors for anastomotic leakage. To identify these potential risk factors, univariate tests were performed using Fisher's exact test (on categorical variables) and the Wilcoxon-MannWhitney test (on continuous variables), both with the binary outcome of anastomotic leakage. The analysis was done using the R-project statistical package (R Foundation for Statistical Computing, 2010, Vienna, Austria). $P$ values of less than 0.05 were considered to be significant. But at this relatively low number of events, variables with $P$ values below 0.3 may still be considered potential predictors and should where possible be included in further studies.

A decision tree was created to identify subgroups with an increased risk of anastomotic leakage. As the statistics are low, the resulting tree should not be used as a predictive model for clinical use. Recursive partitioning using the CHAID algorithm (chi-squared automatic interaction detector) was used to build the decision tree, furthermore the Chordiant Predictive Analytics software (Chordiant Software, 2010, Cupertino, USA) was used.

\section{Results}

During the study period of 24 months, 285 ASA I-III patients underwent colorectal surgery with large bowel anastomoses. Of these 285 patients, 263 patients were scheduled for elective and 22 for emergency surgery. The patient characteristics are shown in Table 1 and the surgical history of patients in Table 2. Over 61\% (175) of the patients had a malignancy, and in $14 \%$ of the patients (40) there was an 'other' indication for surgery such as reversal of a stoma.

In Table 3 the univariate analysis of the risk factors for anastomotic leakage is shown. In 17 cases (6\%), an intraoperative adverse event (such as a lesion of the spleen, ureter, bladder or ileum, torsion of the anastomosis, acute massive bleeding or positive air bubble test) occurred. The anastomotic leak rate was 5.3\% (15 out of 285).

A left side anastomosis $(P<0.001)$ and blood loss as a continuous $(P=0.015)$ and as a categorical variable of $250 \mathrm{~mL}$ or more $(P=0.003)$ were statistically significant risk factors for developing anastomotic leakage. A preoperative high diastolic blood pressure $(P=0.019)$ or as categorical
Table 1 Patient characteristics

Data expressed as mean \pm SD or number (percentage)

$B M I$ body mass index. $A S A$ physical status classification system according to the American Society of Anesthesiologists. MET metabolic equivalent of the task [20]

\begin{tabular}{llllr}
\hline Variable & $\begin{array}{l}\text { Total cohort } \\
(n=285)\end{array}$ & $\begin{array}{l}\text { Cases with } \\
\text { leakage }(n=15)\end{array}$ & $\begin{array}{l}\text { Cases without } \\
\text { leakage }(n=270)\end{array}$ & $P$ value \\
\hline $\begin{array}{l}\text { Age (mean } \pm \text { SD), years } \\
\text { Age } \geq 80 \text { years }\end{array}$ & $67 \pm 14$ & $64 \pm 11$ & $67 \pm 14$ & 0.395 \\
$\begin{array}{l}\text { Gender } \\
\text { Male }\end{array}$ & $50(17.5 \%)$ & $1(6.7 \%)$ & $49(18.1 \%)$ & 0.483 \\
$\begin{array}{l}\text { Female } \\
\text { BMI (mean } \pm \text { SD) }\end{array}$ & $149(52.3 \%)$ & $9(60 \%)$ & $140(51.9 \%)$ & 0.603 \\
$\begin{array}{l}\text { Pts with severe } \\
\text { co-morbidity (ASA } \geq 3)\end{array}$ & $136(47.7 \%)$ & $6(40 \%)$ & $130(48.1 \%)$ & 0.141 \\
MET $\leq 4$ & $25.5 \pm 3.8$ & $26.6 \pm 3.2$ & $25.4 \pm 3.9$ & $>0.999$ \\
\hline
\end{tabular}


Table 2 Surgical history

\begin{tabular}{lllll}
\hline Variable & $\begin{array}{l}\text { Total cohort } \\
(n=285)\end{array}$ & $\begin{array}{l}\text { Cases with } \\
\text { leakage }(n=15)\end{array}$ & $\begin{array}{l}\text { Cases without } \\
\text { leakage }(n=270)\end{array}$ & $P$ value \\
\hline $\begin{array}{l}\text { Smoking } \\
\text { Alcohol } \geq 3 \text { glasses/day }\end{array}$ & $99(34.7 \%)$ & $8(53.3 \%)$ & $91(33.7 \%)$ & 0.262 \\
$\begin{array}{l}\text { Indication } \\
\text { Carcinoma }\end{array}$ & $14(4.9 \%)$ & $2(13.3 \%)$ & $12(4.4 \%)$ & 0.114 \\
Benign & $175(61.4 \%)$ & $12(80 \%)$ & $163(60.4 \%)$ & 0.234 \\
Other & $70(24.6 \%)$ & $3(20 \%)$ & $67(24.8 \%)$ & \\
Previous abdominal surgery & $40(14.0 \%)$ & 0 & $40(14.8 \%)$ & $123(45.6 \%)$ \\
Preoperative radiotherapy & $126(44.2 \%)$ & $3(20 \%)$ & $17(6.3 \%)$ & 0.642 \\
\hline
\end{tabular}

variable of more than $90 \mathrm{mmHg}(P=0.008)$ was also statistically associated with a higher incidence of anastomotic leakage. In 209 cases $(73 \%)$ the maximum decrease in diastolic blood pressure from baseline was greater than $40 \%$. The median duration of such a decrease in diastolic blood pressure was $13 \mathrm{~min}$. From these procedures, 14 cases of anastomotic leakage resulted ( $P=0.127$ for the categorical test and $P=0.049$ for the continuous test of the duration of the decrease).

In our cohort only 20 out of 285 patients $(7 \%)$ underwent preoperative radiotherapy, with 3 out of 20 patients developing an anastomotic leak $(P=0.078)$. Four other factors may be considered potential predictors $(P<0.30)$, suggesting that they
Table 3 Univariate analysis of the risk factors for anastomotic leakage

\footnotetext{
${ }^{a}$ Intraoperative adverse events reported: lesion spleen, ureter, bladder or ileum, torsion of the anastomosis, acute massive bleeding, positive air bubble test
}

\begin{tabular}{|c|c|c|c|c|}
\hline Variable & $\begin{array}{l}\text { Total cohort } \\
(n=285)\end{array}$ & $\begin{array}{l}\text { Cases with } \\
\text { leakage }(n=15)\end{array}$ & $\begin{array}{l}\text { Cases without } \\
\text { leakage }(n=270)\end{array}$ & $P$ value \\
\hline \multicolumn{5}{|l|}{ Surgery } \\
\hline Elective & $263(92.3 \%)$ & $14(93.3 \%)$ & $249(92.2 \%)$ & $>0.999$ \\
\hline Acute & $22(7.7 \%)$ & $1(6.7 \%)$ & $21(7.8 \%)$ & $>0.999$ \\
\hline Laparotomy & $182(63.9 \%)$ & $10(66.7 \%)$ & $172(63.7 \%)$ & $>0.999$ \\
\hline Laparoscopy & $103(36.1 \%)$ & $5(33.3 \%)$ & $98(36.3 \%)$ & $>0.999$ \\
\hline Of which conversion & $28(27.2 \%)$ & $2(40 \%)$ & $26(26.5 \%)$ & 0.649 \\
\hline Anastomosis, right & $84(29.5 \%)$ & 0 & $84(31.1 \%)$ & $>0.999$ \\
\hline Anastomosis, left & $161(56.5 \%)$ & $15(100 \%)$ & $146(4.1 \%)$ & $<0.001$ \\
\hline Other & $40(14.0 \%)$ & 0 & $40(14.8 \%)$ & $>0.999$ \\
\hline Duration of surgery (min) & $241 \pm 82$ & $252 \pm 67$ & $240 \pm 82$ & 0.306 \\
\hline Intraoperative adverse event ${ }^{\mathrm{a}}$ & $17(6.0 \%)$ & $3(20 \%)$ & $14(5.2 \%)$ & 0.050 \\
\hline Total intraoperative fluid intake (mL) & $3513 \pm 1315$ & $3523 \pm 1040$ & $3513 \pm 1331$ & 0.915 \\
\hline Blood loss (mL) & $387 \pm 437$ & $423 \pm 296$ & $384 \pm 446$ & 0.015 \\
\hline Blood loss $\geq 250 \mathrm{~mL}$ & $87(30.5 \%)$ & $10(66.7 \%)$ & $77(28.5 \%)$ & 0.003 \\
\hline Neuraxial technique & $250(87.7 \%)$ & $13(86.7 \%)$ & $237(87.8 \%)$ & 0.390 \\
\hline Preoperative DBP (mmHg) & $81 \pm 12$ & $87 \pm 10$ & $81 \pm 13$ & 0.019 \\
\hline $\mathrm{DBP} \geq 90 \mathrm{mmHg}$ & $79(27.7 \%)$ & $9(60 \%)$ & $70(25.9 \%)$ & 0.008 \\
\hline Preoperative SBP (mmHg) & $141 \pm 20$ & $136 \pm 17$ & $142 \pm 20$ & 0.398 \\
\hline $\mathrm{SBP} \geq 150 \mathrm{mmHg}$ & $92(32.3 \%)$ & $4(26.7 \%)$ & $88(32.6 \%)$ & 0.780 \\
\hline DBP: intraoperative $\downarrow>25 \%$ (yes or no) & $267(93.7 \%)$ & $15(100 \%)$ & $252(93.3 \%)$ & $>0.999$ \\
\hline Duration (min), mean \pm SD & $112 \pm 84$ & $137 \pm 92$ & $111 \pm 84$ & 0.278 \\
\hline Intraoperative $\downarrow$ DBP $>40 \%$ (yes or no) & $209(73.3 \%)$ & $14(93.3 \%)$ & $195(72.2 \%)$ & 0.127 \\
\hline Duration (min), mean $\pm \mathrm{SD}$ & $38 \pm 57$ & $51 \pm 57$ & $37 \pm 57$ & 0.049 \\
\hline SBP: intraoperative $\downarrow>25 \%$ (yes or no) & $263(92.3 \%)$ & $15(100 \%)$ & $248(91.9 \%)$ & $>0.999$ \\
\hline Duration (min), mean $\pm \mathrm{SD}$ & $93 \pm 71$ & $86 \pm 58$ & $93 \pm 72$ & 0.862 \\
\hline Intraoperative $\downarrow$ SBP $>40 \%$ (yes or no) & $205(71.9 \%)$ & $13(86.7 \%)$ & $192(71.1 \%)$ & 0.368 \\
\hline Duration (min), mean $\pm \mathrm{SD}$ & $27 \pm 43$ & $22 \pm 34$ & $28 \pm 43$ & 0.923 \\
\hline Intraoperative use of vasoactive drugs & $213(74.7 \%)$ & $12(80 \%)$ & $201(74.4 \%)$ & 0.768 \\
\hline
\end{tabular}


might be related to anastomotic failure: BMI $(P=0.141)$, smoking ( $P=0.262$ ), severe alcohol consumption ( $\geq 3$ units a day, $P=0.114)$, and the surgical indication being a carcinoma ( $P=0.234$, see Tables 1 and 2 ).

Recursive partitioning using the CHAID algorithm resulted in the decision tree shown in Fig. 1. Notably, this tree identifies a subgroup of patients with a high incidence of leakage that has a high preoperative diastolic blood pressure combined with a significant decrease in diastolic blood pressure during the operation. The subgroup consists of patients with left-sided resection, blood loss of more than $250 \mathrm{~mL}$, preoperative diastolic blood pressure of more than $90 \mathrm{mmHg}$ and a long (more than $7 \mathrm{~min}$ ) period of relative decrease in diastolic blood pressure of more than $40 \%$ from baseline during the operation. This subgroup consists of 18 patients of which 6 developed an anastomotic leakage.

Most patients received epidural analgesia (253 out of 285). In four patients the epidural failed to provide adequate analgesia and was removed on the day of surgery (day 0 ). The median duration of continuation of patient controlled epidural analgesia was 2 (1-10) days, with a mean of 2.59 days. The median duration of hospital stay was $6(1-105)$ days. Postoperative complications ranging from pneumonia to wound infection occurred in 101 patients (35\%). Of the patients with anastomotic leakage, $93 \%$ also developed a second complication (14 out of 15). The mortality rate associated with anastomotic leak was $13 \%$ ( 2 out of 15$)$. The overall mortality rate in the group

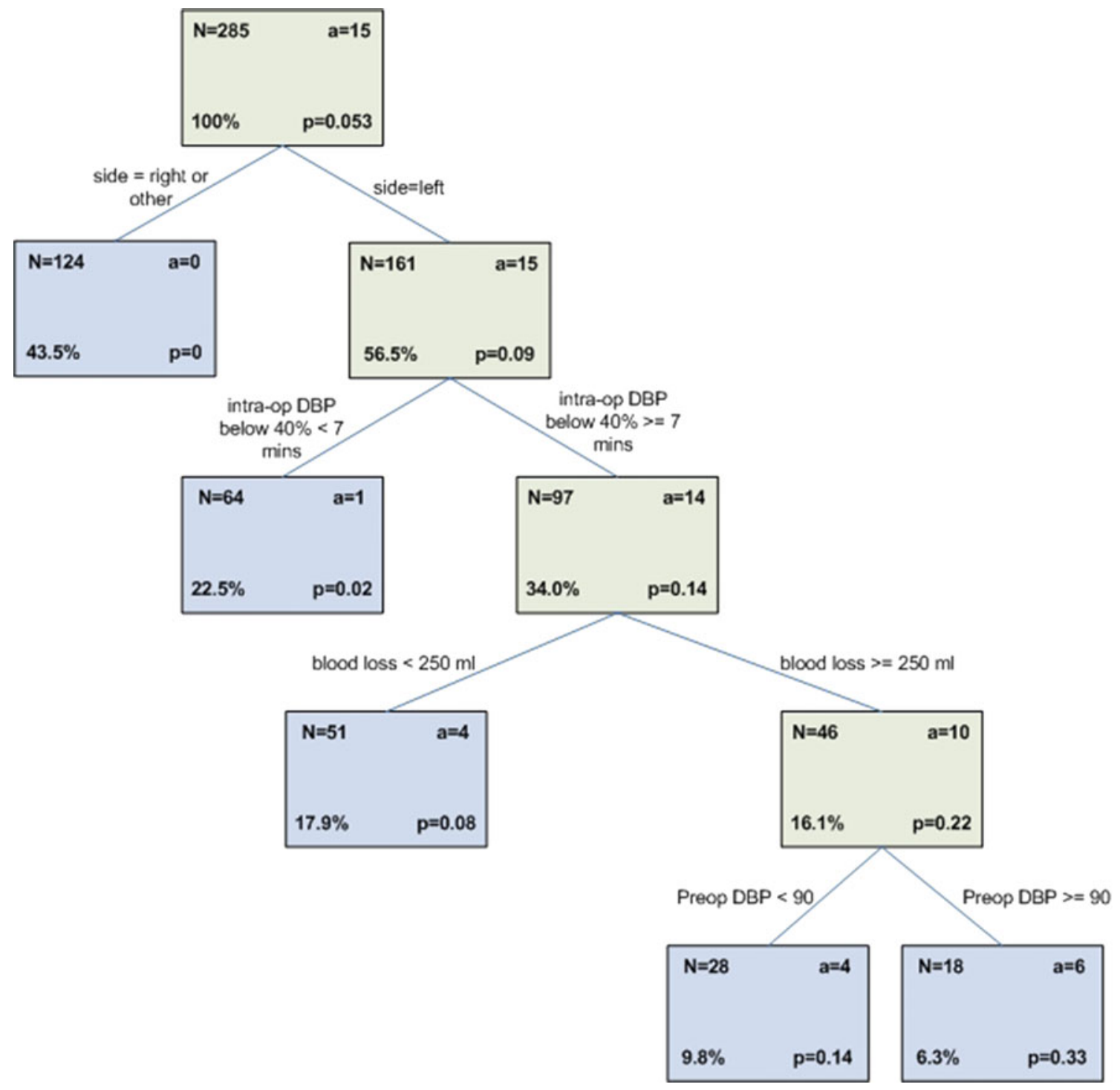

Fig. 1 Decision tree: The overall risk of developing an anastomotic leak is $5.3 \%$ in our population. The subgroup of patients after left-sided resection had an increased risk of $9 \%$. The patients who had a relative decrease in DBP of more than $40 \%$ during the operation had an increased risk of $14 \%$, and their risk further increased to $22 \%$ if intraoperative blood loss was $\geq 250 \mathrm{~mL}$. Patients in this subgroup who had a preoperative DBP of $\geq 90 \mathrm{mmHg}$ had a $33 \%$ increased risk of developing an anastomotic leak 
of patients without anastomotic failure was $0.7 \%$ (2 out of 270 , see Table 4).

\section{Discussion}

There are numerous reports over the association between surgical procedures and surgical outcome such as anastomotic leakage. However, aberrant preoperative and intraoperative hemodynamic status and their influence on adverse outcome after colorectal surgery have not been analysed in detail. Our current study investigates associations between adverse surgical outcome, in particular anastomotic leakage, and intraoperative hemodynamic aberrations. The occurrence of preoperative diastolic hypertension, defined as DBP $\geq 90 \mathrm{mmHg}$ was independently associated with the occurrence of anastomotic leakage, possibly indicating a higher susceptibility for microvascular ischemia due to hypotension at the site of anastomosis. Also severe intraoperative relative hypotension (a relative decrease in diastolic blood pressure of more than $40 \%$ ) was associated with an increased incidence of anastomotic leakage. Although the decrease in diastolic blood pressure was accompanied by a decrease in systolic blood pressure, this drop was less severe and was not of statistical significance. This is probably due to the relatively small population size in our study. The identification of high diastolic blood pressure as a risk factor in our small cohort could be a stimulation to find confirmation in a larger study and in other hospital populations. This outcome may have important consequences when deciding which patient deserves a covering ileostomy and which patient has such a limited risk for anastomotic failure that defunctioning of the anastomotic site is not necessary. Furthermore, an increased awareness of the importance of intraoperative blood pressure control may be necessary.

Besides the vital signs used in the current study, biochemical indicators such as systemic arterial hyperlactatemia may also be important to correctly interpret microcirculation. The systemic concentrations of lactate, however, may vary widely due to overall hemodynamic state and liver function. It has been demonstrated by Deeba et al. [15] that rapid intraluminal sampling microdialysis of glucose and lactate were important parameters for detection of bowel ischemia. Therefore, in a future prospective trial it might be interesting to add intraluminal glucose and lactate measurements.

Various articles describe an increased chance of anastomotic leakage in males because of the smaller pelvis; however, no significant difference was found in our study group. In our cohort colonic surgery and rectal surgery was combined which may be the reason for the lack of difference. Furthermore, in this study, the use of steroids is not evaluated.

All anastomoses were handsewn, except for colorectal anastomoses, which were achieved using a circular stapler. Stapled anastomosis with a circular device is a well-established technique for anastomosis after sigmoid resection or low anterior resection. Results of stapled anastomoses are not inferior to handsewn methods, and therefore, the rate of left-sided anastomotic leak is probably not a result of the use of stapling devices $[16,17]$.

In our study population, most patients (88\%) received (patient controlled) epidural analgesia. We did not control for possible severe sympathicolysis caused by the neuraxial blockade, but by using patient controlled analgesia and avoiding motor blockade, it was our intention to minimize the influence on postoperative blood pressure. With patients undergoing laparoscopic resections, a neuraxial technique might not be necessary and with regards to blood pressure control has to be used with caution.

In contrast to findings in previous studies, we did not find long operation duration as a risk factor for anastomotic leakage. But, the occurrence of intraoperative adverse events $(P=0.050)$ was an indicator for the development of anastomotic leakage. Intraoperative adverse events could be an indication of more complex surgery. Acute massive bleeding was not specifically mentioned as a complication in the leakage group (see Table 5 and 6), but blood loss of $250 \mathrm{~mL}$ or more proved to be a significant independent risk factor for anastomotic failure. The cutoff point of $250 \mathrm{~mL}$ for this continuous variable of blood loss was arbitrary. A recent study from Telem et al. [18] pointed out that blood loss of more than $200 \mathrm{~mL}$ is an independent risk factor. Arbitrarily chosen or not, there are indications that subsequent blood loss during operation is a strong predictor for the development of anastomotic leakage. In our study only 12 out of 285 patients $(4.2 \%)$ needed a blood transfusion of which 1 patient developed an anastomotic leak. Despite the
Table 4 Outcome

${ }^{a}$ Other than anastomotic leak: pneumonia, anaphylactic or septic shock, bleeding, wound infection, abscesses, oedema, bladder dysfunction, gastric perforation

\begin{tabular}{|c|c|c|c|c|}
\hline & $\begin{array}{l}\text { Total cohort } \\
(n=285)\end{array}$ & $\begin{array}{l}\text { Cases with } \\
\text { leakage }(n=15)\end{array}$ & $\begin{array}{l}\text { Cases without } \\
\text { leakage }(n=270)\end{array}$ & $P$ value \\
\hline Development complications $^{\mathrm{a}}$ & $101(35.4 \%)$ & $14(93.3 \%)$ & $87(32.2 \%)$ & $<0.001$ \\
\hline Hospital stay (days) & $10 \pm 11$ & $29 \pm 24$ & $9 \pm 9$ & $<0.001$ \\
\hline Mortality & $4(1.4 \%)$ & $2(13.3 \%)$ & $2(0.7 \%)$ & 0.015 \\
\hline
\end{tabular}


Table 5 Characteristics of patients with anastomotic leakage

\begin{tabular}{|c|c|c|c|c|c|c|c|c|c|}
\hline ID & Procedure & Indication & $\mathrm{M} / \mathrm{F}$ & Age & BMI & ASA & MET & Alcohol & RT \\
\hline 1 & Low anterior resection & Malignancy & $\mathrm{F}$ & 74 & 23 & 3 & $\leq 4$ & $<3$ & Yes \\
\hline 2 & High anterior resection & Malignancy & M & 73 & 29 & 1 & 5 to 8 & None & No \\
\hline 3 & Hemicolectomy & Malignancy & $\mathrm{F}$ & 85 & 27 & 2 & 5 to 8 & $<3$ & No \\
\hline 4 & High anterior resection (conversion) & Diverticulitis & M & 68 & 25 & 1 & 5 to 8 & $<3$ & No \\
\hline 5 & Low anterior resection & Malignancy & M & 50 & 28 & 2 & $\geq 9$ & $>6$ & No \\
\hline 6 & High anterior resection & Diverticulitis & $\mathrm{F}$ & 77 & 29 & 2 & 5 to 8 & None & No \\
\hline 7 & High anterior resection & Stenosis & M & 73 & 24 & 1 & 5 to 8 & $<3$ & No \\
\hline 8 & Low anterior resection & Malignancy & M & 54 & 24 & 1 & 5 to 8 & $<3$ & Yes \\
\hline 9 & Colectomy (conversion) & Malignancy & M & 63 & 26 & 1 & 5 to 8 & $<3$ & Yes \\
\hline 10 & Low anterior resection & Malignancy & M & 67 & 25 & 1 & 5 to 8 & 3 to 6 & No \\
\hline 11 & High anterior resection & Malignancy & $\mathrm{F}$ & 66 & 28 & 2 & 5 to 8 & None & No \\
\hline 12 & High anterior resection & Malignancy & $\mathrm{F}$ & 57 & 32 & 1 & 5 to 8 & $<3$ & No \\
\hline 13 & Low anterior resection & Malignancy & M & 44 & 21 & 2 & 5 to 8 & $<3$ & No \\
\hline 14 & Low anterior resection & Malignancy & $\mathrm{F}$ & 76 & 30 & 2 & $\geq 9$ & $<3$ & No \\
\hline 15 & Low anterior resection & Malignancy & M & 55 & 30 & 2 & $\geq 9$ & $<3$ & No \\
\hline
\end{tabular}

difference in blood loss between the groups who developed anastomotic leakage, blood transfusion-associated immunosuppression is presumably not an obvious explanation.

Patients were evaluated up until 14 days post-discharge. Since anastomotic leakages are detected anywhere from 3 to 40 days postoperatively [19], it is possible that some of the anastomotic leakages were not evaluated. Clinically significant leaks would however almost certainly have been identified, since all patients received follow-up in our surgical outpatient clinic.
The sample size of 285 procedures with 15 anastomotic leakages does not allow the use of multivariate logistic regression. Therefore, this study has focused on a univariate identification of potential risk factors. The risk factors appointed in this study need further evaluation in a large prospective trial. We should be cautious with the interpretation of the results of this small study, but we can point out the potential importance of intraoperative blood pressure control.

Table 6 Intraoperative and postoperative complications of patients with anastomotic leakage

\begin{tabular}{|c|c|c|c|c|c|c|c|c|}
\hline ID & $\begin{array}{l}\text { Blood pressure } \\
(\mathrm{mmHg})\end{array}$ & $\begin{array}{c}\text { Time } \downarrow \text { SBP } \\
>40 \%(\mathrm{~min})\end{array}$ & $\begin{array}{c}\text { Time } \downarrow \text { DBP } \\
>40 \%(\mathrm{~min})\end{array}$ & $\begin{array}{l}\text { Intraoperative } \\
\text { adverse events }\end{array}$ & $\begin{array}{l}\text { Duration of } \\
\text { surgery (min) }\end{array}$ & $\begin{array}{l}\text { Blood } \\
\text { loss }(\mathrm{mL})\end{array}$ & $\begin{array}{l}\text { Postoperative } \\
\text { complication }\end{array}$ & $\begin{array}{l}\text { Hospital } \\
\text { stay (days) }\end{array}$ \\
\hline 1 & $128 / 85$ & 11 & 42 & & 211 & 300 & Wound infection & 25 \\
\hline 2 & $151 / 90$ & 126 & 109 & & 317 & 600 & $\begin{array}{l}\text { Pneumonia, } \\
\text { wound infection }\end{array}$ & 34 \\
\hline 3 & $158 / 61$ & 47 & 7 & & 297 & 250 & Stomach perforation & 9 \\
\hline 4 & $130 / 95$ & 5 & 8 & & 306 & 300 & & 5 \\
\hline 5 & $122 / 75$ & 0 & 0 & & 298 & $<150$ & Multiple abcesses & 60 \\
\hline 6 & $110 / 90$ & 3 & 128 & Lesion bladder & 393 & 1,180 & Septic shock & 27 \\
\hline 7 & $165 / 95$ & 1 & 26 & Lesion ureter & 181 & 400 & Double J catheter ureter & 15 \\
\hline 8 & $140 / 80$ & 0 & 15 & $\begin{array}{l}\text { Torsion } \\
\text { anastomosis }\end{array}$ & 158 & 250 & Pneumonia & 6 \\
\hline 9 & $144 / 99$ & 55 & 89 & & 305 & 300 & $\begin{array}{l}\text { Abdominal compartment } \\
\text { syndrome, pneumonia }\end{array}$ & 4 \\
\hline 10 & $105 / 80$ & 5 & 49 & & 215 & 200 & Wound infection & 49 \\
\hline 11 & $136 / 92$ & 29 & 42 & & 299 & 200 & Wound infection & 28 \\
\hline 12 & $120 / 90$ & 6 & 20 & & 234 & $<150$ & Wound infection & 30 \\
\hline 13 & $130 / 95$ & 2 & 204 & & 366 & 800 & Wound infection & 33 \\
\hline 14 & $154 / 87$ & 37 & 7 & & 315 & 300 & Wound dehiscence & 94 \\
\hline 15 & $145 / 95$ & 10 & 25 & & 329 & $<150$ & Cardiac arrythmias & 19 \\
\hline
\end{tabular}

Patients 3 and 9 died during the study, see also Table 4 (Outcome) 


\section{Conclusion}

In our study several preoperative and intraoperative factors were demonstrated to be associated with the postoperative development of an anastomotic leak. In particular, high preoperative diastolic blood pressure and longer episodes of severe intraoperative hypotension, combined with complex surgery (marked by blood loss of $\geq 250 \mathrm{~mL}$ ) and the occurrence of intraoperative adverse events, resulted in a significant increase in the development of anastomotic leakage. This could be an indication that hypotension should be avoided, particularly in patients with high preoperative blood pressures.

Proximal diversion does not prevent anastomotic leakage and leads in its own right to morbidity. In patients with multiple risk factors for the development of an anastomotic leak, however, one can imagine that a proximal diversion could lessen the dreaded sequelae should a leak occur.

Open Access This article is distributed under the terms of the Creative Commons Attribution Noncommercial License which permits any noncommercial use, distribution, and reproduction in any medium, provided the original author(s) and source are credited.

\section{References}

1. Biondo S, Pares D, Kreisler E et al (2005) Anastomotic dehiscence after resection and primary anastomosis in left-sided colonic emergencies. Dis Colon Rectum 48:2272-2280

2. Choi HK, Law WL, Ho JW (2006) Leakage after resection and intraperitoneal anastomosis for colorectal malignancy: analysis of risk factors. Dis Colon Rectum 49:1719-1725

3. Yeh CY, Changchien CR, Wang J-Y et al (2005) Pelvic drainage and other risk factors for leakage after elective anterior resection in rectal cancer patients: a prospective study of 978 patients. Ann Surg 241:9-13

4. Lipska MA, Bisset IP, Parry BR, Merrie AE et al (2006) Anastomotic leakage after lower gastrointestinal anastomosis: men are at a higher risk. ANZ J Surg 76:579-585

5. Sorensen LT, Jorgensen T, Kirkeby LT, Skovdal J, Vennits B, WilleJorgensen P (1999) Smoking and alcohol abuse are major risk factors for anastomotic leakage in colorectal surgery. Br J Surg 86:927-931

6. Kingham TP, Pachter HL (2009) Colonic anastomotic leak: risk factors, diagnosis and treatment. J Am Coll Surg 208(2):269-278
7. Boyle NH, Manifold D, Jordan MH, Mason RC (2000) Intraoperative assessment of colonic perfusion using scanning laser Doppler flowmetry during colonic resection. J Am Coll Surg 191:504-510

8. Vignali A, Gianotti L, Braga M et al (2000) Altered microperfusion at the rectal stump is predictive for rectal anastomotic leak. Dis Colon Rectum 43:76-82

9. Mancia G, De Backer G, Dominiczak A, Cifkova R, Fagard R, Germano G, Grassi G, Heagerty AM, Kjeldsen SE, Laurent S, Narkiewicz K, Ruilope L, Rynkiewicz A, Schmieder RE, Struijker Boudier HA, Zanchetti A (2007) The Task Force for the Management of Arterial Hypertension of the European Society of Hypertension (ESH) and of the European Society of Cardiology (ESC). Eur Heart J 28:1462-1536

10. Goldman L, Caldera DL (1979) Risks of general anesthesia and elective operation in the hypertensive patient. Anesthesiology 50:285

11. Reich DL, Wood RK Jr, Emre S, Bodian CA, Hossain S, Krol M, Feierman D (2003) Association of intraoperative hypotension and pulmonary hypertension with adverse outcomes after orthoptopic liver transplantation. J Cardiothorac Vasc Anesth 17 (6):699-702

12. Sandid MS, Assi MA, Hall S (2006) Intraoperative hypotension and prolonged operative time as risk factors for slow graft function in kidney transplant recipients. Clin Transplant 20:762-768

13. Zakrison T, Nascimento BA Jr, Tremblay LN, Kiss A, Rizoli SB (2007) Perioperative vasopressors are associated with an increased risk of gastrointestinal anastomotic leakage. World J Surg 31:1627-1634

14. Bijker JB, van Klei WA, Vergouwe Y, Eleveld DJ, van Wolfswinkel L, Moons KG, Kalkman CJ (2009) Intraoperative hypotension and 1-year mortality after noncardiac surgery. Anesthesiology 111:1217-1226

15. Deeba S, Corcoles EP, Hanna BG, Pareskevas P, Azis O, Boutelle MG, Darzi A (2008) Use of rapid sampling microdialysis for intraoperative monitoring of bowel ischemia. Dis Colon Rectum 51:1408-1413

16. Lustosa SA, Matos D, Atallah AN, Castro AA (2001) Stapled versus handsewn methods for colorectal anastomosis surgery. Cochrane Database Syst Rev 2001;(3):CD003144

17. MacRae HM, McLeod RS (1998) Handsewn versus stapled anastomoses in colon and rectal surgery: a meta-analysis. Dis Colon Rectum 41(2): 180-189

18. Telem DA, Chin EH, Nguyen SQ, Divino CM (2010) Risk factors for anastomotic leak following colorectal surgery. Arch Surg 145 (4):371-376

19. Hyman N, Manchester TL, Osler T, Burns B, Cataldo PA (2007) Anastomotic leaks after intestinal anastomosis: it's later than you think. Ann Surg 245:254-258

20. Jette M, Sidney K, Blumchen G (1990) Metabolic equivalents (METs) in exercise testing, exercise prescription and evaluation of functional capacity. Clin Cardiol 13:555-565 